\title{
Problemas relacionados ao uso de Esteroides Anabólicos Androgênicos (EAA) por praticantes de musculação e o papel do farmacêutico na educação destes atletas de modo a reduzir o uso indiscriminado
}

\author{
Problems related to the use of Anabolic Androgenic Steroids (AAS) \\ by practitioners of weight training and the role of the pharmacist in \\ education of these athletes in order to reduce indiscriminate use
}

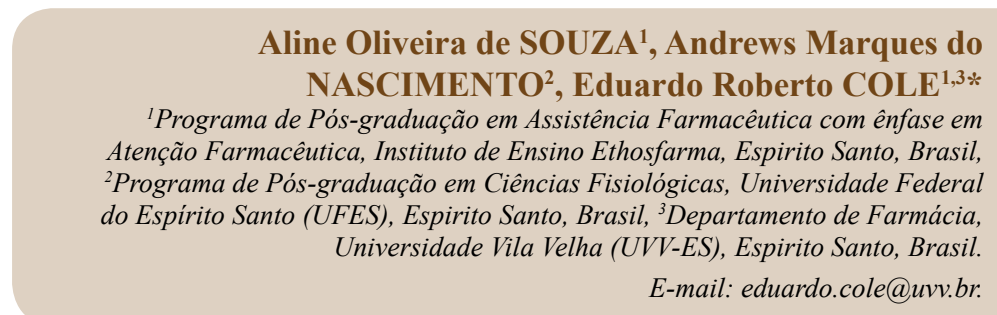

\section{ABSTRACT}

The seeking for the perfect body is assuming alarming proportions among the world. The cult of the body triggered a frantic search for devices designed to achieve ideal beauty unrealistic for most people. Among these artifacts, we highlight the use of anabolic androgenic steroids (AAS), which have similar effects of testosterone, increasing the force of contraction and the volume of muscle cells. The pharmacist as professional duly qualified drugs, fits into this context decisively, assuming the role of "health educator", and explaining to users (or prospective users) about the risks inherent in such a practice, acting decisively in discouraging the use of AAS in drugstores when faced with individual's intent on making non-medical use/illicit AAS, looking always flee from traditional approaches that awareness campaigns (that few results have been obtained in recent years).

KEY WORDS: Testosterone; pharmacy; anabolic, academy.

\section{RESUMO}

A busca pelo corpo perfeito está assumindo proporções assustadoras em todas as partes do mundo. O culto ao corpo desencadeou uma busca desenfreada por artifícios que permitam alcançar um ideal de beleza fora da realidade para a maior parte da população. Dentre estes artifícios, destaca-se o uso de esteroides anabólicos androgênicos (EAA), que apresentam efeitos semelhantes aos da testosterona, promovendo aumento da força de contratilidade e do volume das células musculares. O farmacêutico, enquanto profissional devidamente habilitado em medicamentos, insere-se neste contexto de forma decisiva, assumindo o papel de "educador em saúde", esclarecendo aos usuários (ou futuros usuários) sobre os riscos inerentes a tal prática, atuando de forma decisiva no desencorajamento do uso de EAA ao se depararem nas drogarias com indivíduos intencionados a fazer o uso não médico/ilícito de EAA, procurando sempre abordagens que fujam das tradicionais campanhas de conscientização (que poucos resultados têm obtido nos últimos anos).

PALAVRAS-CHAVE: Testosterona; farmácia; anabolizantes; academia 


\section{LISTA DE ABREVIAÇÕES:}

EAA Esteroides anabólicos androgênicos

CEBRID Centro Brasileiro de Informações sobre Drogas Psicotrópicas

LH Hormônio luteinizante

RA Receptor Androgênico

DHT Diidrotestosterona

AIDS Acquired immunodeficiency syndrome

LDL Low-density lipoprotein

HDL High-density lipoprotein

TSH Hormônio tireoestimulante

HIV Human immunodeficiency virus

ATLAS Adolescents Training and Learning to Avoid Steroids.

\section{INTRODUÇÃO}

A busca pelo corpo perfeito está assumindo proporções assustadoras em todas as partes do mundo. $\mathrm{O}$ culto ao corpo desencadeou uma busca desenfreada por artifícios que permitam alcançar um ideal de beleza fora da realidade para a maior parte da população, dentre os quais se destaca o uso de esteroides anabólicos androgênicos (EAA).

Homens de todas as idades, em números sem precedentes, estão preocupados com a aparência de seus corpos. Sacrificam aspectos importantes de suas vidas para exercitar-se compulsivamente nas academias. Esta forma de obsessão pela aparência corporal que transcende a linha do interesse normal para tornar-se obsessão patológica denomina-se Complexo de Adônis, um termo não oficial utilizado pela medicina para indicar um conjunto de preocupações com a imagem corporal entre os homens. Essas preocupações vão de pequenos desgostos até obsessões devastadoras e às vezes perigosas para a vida. Os distúrbios com a aparência corporal em homens são pouco conhecidos pois tanto pesquisadores quanto a imprensa em geral concluíram durante décadas que os problemas com a imagem corporal e os distúrbios alimentares são doenças das mulheres (1).

Os homens estão cada vez mais cercados pela mídia com imagens de perfeição masculina, sendo levados a sentir-se cada vez mais desajustados quanto à própria aparência, ao mesmo tempo em que apresentam receio de falar a respeito ou mesmo admitir, pois ainda trabalham um tabu social contra a expressão de tais sentimentos. Muitos pais não sabem que seus filhos fazem uso de esteroides anabolizantes, acreditando que o rápido ganho muscular se deva apenas a um trabalho duro, dieta equilibrada e suplementação proteica (1).

Nenhuma das gerações anteriores sofreu tanta influência de padrões estéticos de imagem corporal; em parte porque não se tinha a presença de fármacos que permitissem tais efeitos anabólicos. O homem moderno raramente percebe quanto de sua autoestima e noção de masculinidade estão ligados às preocupações com a imagem corporal. Em consequência destes sentimentos, podem se tornar cada vez mais concentrados nas deficiências de seus corpos, sem realmente compreender o motivo (1).

Várias investigações demonstram que os usuários de EAA frequentemente estão insatisfeitos com seus corpos e apresentam baixa autoestima, o que os torna mais susceptíveis ao abuso de tais fármacos (2).

A crise da imagem corporal masculina provavelmente está relacionada com dois fatores socioculturais importantes que distinguem a geração atual de todas as gerações anteriores: a disponibilidade de fármacos capazes de interferir na estética masculina, dentre as quais se destacam os EAA, e a crescente igualdade entre homens e mulheres (1).

A utilização dos EAA proporcionou atletas, atores e modelos maiores e mais fortes do que o padrão de homem considerado comum, e, a mídia difundiu suas imagens por toda parte. Essas imagens glorificaram os corpos produzidos por tais fármacos, retratando-os como um modelo de saúde, capacidade atlética, trabalho duro e dedicação (embora quase nunca admitindo tratar-se de perigosas substâncias químicas) (1).

Os EAA apresentam efeitos semelhantes aos da testosterona, principal hormônio sexual masculino. São consumidas por atletas que, com isso, esperam aumentar a massa corporal pouco desenvolvida, a força muscular e a resistência física (3).

Embora tais fármacos, sem receita médica, sejam ilegais nos Estados Unidos e em muitos outros países, incluindo o Brasil, estão amplamente disponíveis graças a um vasto mercado negro, no qual até mesmo adolescentes podem comprá-los (1).

O uso de EAA tornou-se epidêmico, pois ao contrário do que dizem alguns mitos, eles são extremamente eficazes na hipertrofia da musculatura, principalmente em altas doses (4), tornando até mesmo um atleta medíocre mais musculoso do que um atleta dedicado e esforçado.

Com o intuito de reduzir o uso indiscriminado de EAA, alguns mitos foram criados, principalmente pela comunidade médica e científica. Durante anos, muitos e reputados livros de farmacologia, endocrinologia e clínica médica afirmaram simplesmente que tais fármacos não possuíam qualquer capacidade comprovada de ajudar as pessoas a ganhar massa muscular. Entretanto, a maior parte destes estudos utilizou doses de EAA ridiculamente baixas em comparação com as doses realmente usadas por atletas. Outro mito desmascarado foi a rápida 
perda da musculatura conquistada após o término da utilização dos EAA. Hoje, a maior parte das autoridades concorda que os EAA realmente funcionam e que esses efeitos em longo prazo os tornam quase únicos entre os fármacos sujeitos a abuso (1).

Os usuários de EAA raramente apresentam complicações médicas óbvias durante o uso. Mesmo com a divulgação de diversos materiais educativos, tentando evitar o uso de EAA, dramatizando os efeitos clínicos em longo prazo, os usuários raramente se preocupam com eles (1).

Pesquisas indicam que muitos jovens estão utilizando estas substâncias para melhorar a aparência física, e não necessariamente para melhorar o desempenho esportivo (3). Alguns adolescentes abusam de EAA como parte de um padrão de comportamento de alto risco, o que é típico da adolescência (5). Os usuários acreditam que os EAA ajam tanto de maneira direta, ocasionando hipertrofia muscular, quanto indireta, proporcionando "sessões de atividade física mais intensa", por tornarem o usuário mais disposto, menos fatigável e mais motivado (6).

Aqueles que perseveram no ritual do culto ao corpo, quase em sua totalidade desejam atingir o resultado esperado de maneira instantânea ou quase. Apesar de a idéia de entrar em forma rapidamente já ter tomado conta dos desejos de muita gente, é preciso salientar que tal modificação não pode ser considerada biologicamente viável, obviamente, se desconsideradas as intervenções cirúrgicas e similares e o uso de fármacos disponibilizados pela indústria farmacêutica (7).

No Brasil, a facilidade em obter os EAA favoreceu sua disseminação junto aos atletas e não atletas. A grande "atração" para o consumo destes fármacos ocorre porque seus efeitos são visíveis e relativamente duradouros (até nove meses após o término do uso). Estas duas características, somadas ao apelo à aparência física, em nossa sociedade, levaram o consumo de EAA a uma faixa etária problemática: a pré-adolescência e a adolescência $(8,9)$.

Essas substâncias são indicadas e muitas vezes vendidas pelos próprios instrutores ou professores das academias, bem como por praticantes veteranos, sendo facilmente encontradas e disponibilizadas para a compra em farmácias (8).

Apesar do aumento na divulgação sobre os riscos relacionados ao uso dos EAA (incluindo campanhas), ainda existe uma descrença muito grande sobre a magnitude de tais riscos. É preciso uma intensificação de ações em termos educacionais a fim de reduzir estes índices de consumo.

O farmacêutico, enquanto profissional devidamente habilitado em medicamentos, insere-se neste contexto de forma decisiva, assumindo o papel de "educador em saúde", e esclarecendo aos usuários (ou futuros usuários) sobre os riscos inerentes a tal prática.

\section{ASPECTOS EPIDEMIOLÓGICOS}

Segundo especialistas, o problema relacionado ao abuso de EAA não está em atletas profissionais, mas em usuários inconformados com seu padrão físico e estético. Esse uso estético não é médico, portanto, é ilegal e ainda acarreta complicações à saúde (10).

Os principais usuários destes fármacos são atletas, porém o uso disseminou também entre os não atletas que buscam um ganho de massa muscular mais rápido. Os homens são ainda os principias usuários, mas a utilização por mulheres vem crescendo consideravelmente $(10,11)$.

Segundo o Centro Brasileiro de Informações sobre Drogas Psicotrópicas (CEBRID), em 2009, no Brasil, não se tinha estimativa deste uso ilícito, mas sabia-se que o consumidor preferencial estava entre 16 e 34 anos de idade e em geral era do sexo masculino (12).

$\mathrm{O}$ emprego desses fármacos tem se tornado uma opção disseminada entre frequentadores das academias. Segundo pesquisa realizada por Iriart \& Andrade (2002), está crescendo entre os jovens brasileiros, mais especificamente nas academias de musculação, o número de usuários de EAA. Apesar de investigações desta natureza (que revelam o uso dos referidos produtos também por indivíduos iniciantes) precisarem ser mais exploradas no Brasil com o intuito de se obter a real dimensão de utilização, tal fato pode ser confirmado por certos indícios empíricos in loco, sendo o principal deles a rapidez com que os músculos de praticantes novatos na musculação aumentam de volume. $\mathrm{O}$ estudo dos pesquisadores reforça a idéia de que esse tipo de "mercadoria" está sendo espalhada facilmente, tornando-se cada dia mais popular (7).

Estudos reportam que $20 \%$ dos atletas colegiais têm usado EAA. Alarmantemente, 4\% a 11\% dos estudantes do sexo masculino e $0,5 \%$ a $2,5 \%$ do sexo feminino do ensino médio já experimentaram estes fármacos (13). Uma pesquisa realizada por Andrade et al. (2012) revelou que $1,9 \%$ e $2,8 \%$ dos alunos da sétima e da oitava séries, respectivamente, responderam ter feito uso de EAA nos 30 dias anteriores (14).

Em 2004, a instituição The Hormone Foundation relatou que de 1966 até 2004, o uso de EAA por adolescentes da oitava série havia aumentado em 39\%, e em $69 \%$ entre os adolescentes do ensino médio (15).

Esteroides anabólicos androgênicos ilícitos nos Estados Unidos passaram a ser vendidos com frequência em academias, em competições e por meio da internet, desde que começaram a ser contrabandeados de países 
que não requerem prescrição para serem comprados. Os EAA também são ilegalmente desviados de farmácias ou sintetizados em laboratórios clandestinos (5).

$\mathrm{O}$ abuso de EAA afeta indivíduos de várias idades. Entretanto, é difícil estimar a verdadeira prevalência do abuso de EAA nos Estados Unidos, porque muitas fontes de dados que mensuram o abuso de fármacos não incluem EAA. Evidências científicas indicam que o abuso de EAA entre atletas pode alcançar de 1\% a $6 \%$ (5).

A maioria dos usuários de EAA muito comumente usa estes fármacos por um período limitado, possivelmente restrito apenas ao uso experimental, sendo que, geralmente, apenas aproximadamente $6,5 \%$ desses indivíduos continuam o uso (16).

Frizon et al. (2005), avaliando o consumo e o comportamento dos usuários de EAA, praticantes de atividade física, nas grandes academias de Erechim e Passo Fundo (RS), utilizaram questionários auto-aplicáveis, disponibilizados nas academias para que fossem respondidos anônima e voluntariamente pelos praticantes (17). Dos 700 questionários distribuídos, 418 questionários foram respondidos. Com relação à faixa etária, metade dos praticantes tinha idade entre 21 e 25 anos. Foi observado que $6,5 \%$ (27 usuários) do total de pessoas que responderam ao questionário, relataram uso, pelo menos uma vez, de EAA. A dose utilizada por eles era, em geral, cerca de cinco vezes a dose usual terapêutica. Todos os voluntários que declararam fazer uso de EAA eram homens e os principais motivos do uso eram benefícios estéticos e o ganho de força. Dez $(37,04 \%)$ destes vinte e sete usuários relataram que a obtenção dos EAA ocorreu em farmácias com receita médica, oito $(25,92 \%) \mathrm{em}$ farmácias sem a apresentação da prescrição médica, e nove $(33,33 \%)$, em outros estabelecimentos comerciais (17). Essa pesquisa revelou que a relação entre o meio de obtenção dos medicamentos na farmácia com prescrição médica $(37,04 \%)$ e sem prescrição médica $(25,92 \%)$ se encontra muito próxima, o que mostra a falta de fiscalização sanitária e ética de alguns profissionais. A obtenção de EAA em estabelecimentos farmacêuticos somente poderia ser realizada por meio de receituário de controle especial em duas vias.

O índice de uso pode estar subestimado, uma vez que a tendência é que usuários de EAA, por reconhecerem a atividade ilegal, se sintam inibidos a preencher o questionário de forma voluntária. Traçando-se o perfil dos usuários, verificou-se que são homens jovens, estudantes universitários e motivados simplesmente pela estética. $\mathrm{O}$ fato de terem um curso superior e teoricamente, um maior conhecimento dos riscos associados ao uso de EAA, não evitou o uso dos mesmos (17).

Considerando os possíveis efeitos colaterais, é possível que o uso de EAA possa se tornar um problema de saúde pública. Por essa razão, em 1990, o Congresso dos EUA aprovou lei que os torna fármacos de uso controlado, ou seja, que exigem receita especial, controlada pelo governo, para sua obtenção (18).

Com o objetivo de realizar um levantamento do perfil dos usuários de EAA frequentadores de academias da Grande Vitória-ES, discentes do curso de Farmácia da Universidade Vila Velha realizaram um estudo nos meses de setembro a novembro de 2006, envolvendo 48 indivíduos frequentadores de academia da Grande Vitória, que são ou já foram usuários de EAA. Os entrevistados que declararam ser usuários $(41,7 \%)$ ou ex-usuários $(58,3 \%)$ de EAA são, em sua totalidade, do sexo masculino, sendo que a estética corporal $(86 \%)$ e o desempenho atlético (12\%) foram os principais motivos relatados pelos entrevistados para o uso. Quanto à forma de aquisição, pôde-se observar que a maioria dos entrevistados adquiriu os EAA de forma ilícita em farmácias $(69 \%)$ ou com instrutores $(11 \%)$ e amigos das academias (20\%), e, a maioria $(66,7 \%)$ declarou ter percebido pelo menos um efeito adverso durante a utilização dos mes$\operatorname{mos}(19)$.

\section{ESTEROIDES ANABÓLICOS ANDROGÊNICOS: CARACTERÍSTICAS FARMACOLÓGICAS}

A testosterona é o principal androgênio circulante nos homens. É secretada pelas células de Leydig dos testículos em resposta ao hormônio luteinizante (LH) hipofisário. Os diversos efeitos da testosterona devem-se à sua capacidade de atuar por meio de pelo menos três mecanismos diferentes: (a) ligação ao receptor androgênico; (b) conversão em certos tecidos em diidrotestosterona, que também se liga ao receptor androgênico; (c) e conversão em estradiol, que se liga ao receptor estrogênico. A testosterona é responsável pela diferenciação sexual masculina in útero e pelas alterações masculinas na puberdade. Nas mulheres o papel fisiológico da testosterona e as consequências de sua deficiência ainda não são conhecidos, mas é possível que contribuam para a libido, a energia, a massa e a força muscular, e para a densidade óssea (20).

A magnitude da secreção de testosterona é maior nos homens do que nas mulheres em quase todas as etapas da vida, o que explica quase todas as outras diferenças existentes entre homens e mulheres. Durante a puberdade as concentrações séricas de testosterona nos homens aumentam muito mais do que nas mulheres, de modo que no início da idade adulta a concentração sérica de testosterona é de 500-700 ng/dL nos homens, comparado com 30-50 ng/dL nas mulheres. A magnitude da concentração nos homens é responsável pelas alterações da puberdade que diferenciam ainda mais os homens das mulheres. À medida que o homem envelhece suas concentrações séricas de testosterona gradualmente 
diminuem o que pode contribuir para outros efeitos do envelhecimento (20).

A enzima $5 \alpha$-redutase catalisa a conversão da testosterona em diidrotestosterona (DHT). Embora a ação tanto da testosterona quanto da DHT ocorra através do mesmo receptor, o receptor androgênico, a DHT se liga com maior afinidade e ativa a expressão do gene com mais eficiência. Como resultado, a testosterona, atuando através da DHT, é capaz de provocar em tecidos que expressam a $5 \alpha$-redutase, efeitos que não poderia provocar se estivesse presente apenas como testosterona (20).

O complexo de enzimas aromatase, presente em muitos tecidos (em especial nos tecidos hepático e adiposo) catalisa a conversão irreversível de testosterona em estradiol. Essa conversão resulta em aproximadamente $85 \%$ do estradiol circulante nos homens; o restante é secretado diretamente pelos testículos (20).

A testosterona é metabolizada no fígado em androsterona e etiocolanolona, que não têm atividade biológica. A diidrotestosterona é metabolizada em androsterona, androstenediona e androstenediol (20).

Os EAA aumentam a massa magra corporal e estimulam o crescimento de pelo corporal e a secreção de sebo. Seus efeitos metabólicos incluem a redução de proteínas carreadoras de hormônios e aumento da síntese hepática dos fatores da coagulação, da triglicerídeo lipase, da $\alpha 1$-antitripsina, da haptoglobina e do ácido siálico. Eles também estimulam a secreção de eritropoietina e diminuem os níveis de lipoproteínas de alta densidade (HDL). Estudos recentes sugerem que, em homens, os hormônios diidroepiandrosterona e o sulfato de diidroepiandrosterona podem melhorar o senso de bem-estar e inibir a aterosclerose (21).

O efeito anabólico da testosterona corresponde à sua propriedade de promover um aumento da massa muscular, através da hipertrofia de fibras musculares, devido ao aumento da síntese protéica intracelular. Os EAA sintéticos conseguem potencializar este efeito, promovendo aumento da força de contratilidade e do volume da célula muscular, através dos seguintes mecanismos: incremento da armazenagem de fosfocreatina; balanço nitrogenado positivo; maior retenção de glicogênio; favorecimento da captação de aminoácidos; bloqueio do cortisol (22).

$\mathrm{O}$ efeito androgênico da testosterona ocasiona o desenvolvimento das características sexuais secundárias masculinas e a maturação dos órgãos reprodutores masculinos (crescimento do pênis e do escroto; aparecimento de pelos púbicos, axilares e de barba; crescimento da laringe e espessamento das cordas vocais, resultando numa voz de timbre baixo; maior ativação das glândulas sebáceas e espessamento da pele; alterações psicológicas e comportamentais). São justamente as propriedades andrógenas dos EAA que resultam em efeitos colaterais e contraindicações (22). Os efeitos androgênicos e anabólicos da testosterona encontram-se relacionados no Quadro 1.

Quadro 1 - Efeitos androgênicos e anabólicos da Testosterona.

\begin{tabular}{|c|}
\hline Efeitos androgênicos \\
\hline Crescimento do pênis \\
\hline Espessamento das cordas vocais \\
\hline Aumento da libibo \\
\hline Aumento da secreção das glândulas sebáceas \\
\hline Aumento de cabelos do corpo e da face \\
\hline Padrão masculino de pelos pubianos \\
\hline
\end{tabular}

Fonte: adaptado de Silva et al. (2002) (38).

Décadas atrás, pesquisadores tentaram sintetizar análogos da testosterona que tivessem maiores efeitos anabolizantes do que androgênicos em comparação com a testosterona ativa. Vários compostos pareceram apresentar tais efeitos, sendo a maioria androgênios $17 \alpha$-alquilados. No entanto, nenhum desses compostos se mostrou capaz desse efeito diferencial em seres humanos. Apesar disso, ganharam popularidade entre os atletas que tentam melhorar seu desempenho (20).

Cunha et al. (2005), para avaliar em ratos os efeitos da nandrolona e do treinamento físico aeróbio sobre o peso corporal, as concentrações plasmáticas de triglicerídeos e glicose e as reservas hepáticas e musculares de glicogênio, utilizaram em seu experimento ratos Wistar com dois meses de idade (23). Os animais foram divididos em quatro grupos experimentais: sedentário + veículo; treinado + veículo; sedentário + EAA; treinado + EAA (n=7-14/grupo). A dose do EAA nandrolona utilizada foi aproximadamente 65 vezes maior do que a indicada. O programa de treinamento consistiu em sessões diárias de natação cinco dias por semana. Ao final do período de nove semanas de treinamento, os animais 
foram mantidos em repouso por 14 horas após a última sessão de exercícios. Os resultados mostraram que o tratamento com EAA exerceu efeito negativo significativo sobre o ganho de peso corporal somente no grupo sedentário. Acredita-se que esta diferença não tenha sido observada entre os animais treinados porque neste caso o próprio treinamento físico promoveu as adaptações necessárias para redução do peso corporal dos animais, não havendo efeito adicional do EAA. Apesar dos EAA estimularem a síntese protéica e aumentarem a retenção hídrica, o que poderia acarretar aumento do peso corporal, sabe-se que em concentrações excessivas podem inibir o crescimento e o ganho de peso corporal. O uso de doses excessivas de EAA também promove alterações no metabolismo lipídico. Entretanto, verifica-se que tais alterações estão relacionadas às concentrações circulantes de lipoproteínas, não exercendo influência direta sobre as concentrações plasmáticas de triglicerídeos. Com exceção do efeito atenuante exercido sobre o peso corporal, o uso de doses suprafisiológicas de EAA no regime estabelecido não promoveu nenhuma alteração dos parâmetros analisados, adicional àquelas obtidas em resposta ao treinamento físico.

\section{INDICAÇÕES}

\section{FARMACOTERAPÊUTICAS DOS EAA}

A indicação mais clara para a administração de EAA é a deficiência de testosterona em homens, isto é, o tratamento do hipogonadismo masculino (20), sendo usados para substituir ou aumentar a secreção endógena de EAA. Até na presença de deficiência pituitária, os EAA são usados preferencialmente à gonadotropina, exceto quando a espermatogênese encontra-se normal. Em pacientes com hipopituitarismo, os EAA não são adicionados ao regime de tratamento antes da puberdade. O tratamento é instituído com aumentos graduais nas doses para produzir o estirão do crescimento e o desenvolvimento das características sexuais secundárias (21).

Evidências preliminares sugerem que o aumento da concentração sérica de testosterona em homens cujos níveis séricos estão abaixo do normal em virtude da idade aumenta a densidade mineral óssea e a massa magra e reduz a massa adiposa. No entanto, hoje é inteiramente incerto se esse tratamento agrava a hiperplasia benigna da próstata ou aumenta a incidência de câncer de próstata clinicamente detectável (20).

Os EAA têm aplicação médica em conjunto com medidas dietéticas e exercícios físicos na tentativa de reverter à perda proteica após trauma, cirurgia, ou imobilização prolongada e em pacientes com doenças debilitantes (21).

Alguns tipos de impotência podem ser tratados usando-se os EAA. Estes também estimulam o início da puberdade em rapazes com mais de 15 anos de idade nos quais esse processo ainda não começou (24).
Os efeitos sobre o desenvolvimento muscular são explorados para tratar a perda muscular severa. Há vários relatos de pacientes com AIDS que experimentaram aumento no apetite, força e massa muscular, além de uma melhora no senso de bem-estar após o uso de EAA. Apesar dos potenciais efeitos colaterais destas substâncias, nestes pacientes seu uso é justificado pela urgente necessidade médica (24).

Os EAA são usados ocasionalmente no tratamento de certas desordens ginecológicas, mas eles devem ser usados com precaução devido aos seus efeitos indesejáveis nas mulheres. Eventualmente, são administrados em combinação com estrógenos na terapia de reposição no período pós-menopausa na tentativa de eliminar o sangramento endometrial que pode ocorrer quando apenas estrógenos são usados para realçar a libido (21).

O tratamento crônico com EAA de pacientes com edema angioneurótico previne os episódios com eficácia (20).

Os EAA já foram utilizados na tentativa de estimular a eritropoiese em pacientes com anemia de várias etiologias, mas a disponibilidade da eritropoietina suplantou sua utilização (20).

\section{UTILIZAÇÃO"NÃO-FARMACOTERAPÊUTICAS" DE ESTEROIDES ANABÓLICOS ANDROGÊNICOS (EAA)}

As maiores diferenças entre o uso médico dos EAA e o abuso recreativo destes fármacos são a dosagem e a rotina de administração praticada pelos usuários ilegais. Frequentemente, o uso médico é realizado a um nível fisiológico, com intervalos regulares de uso. Os usuários recreativos geralmente realizam um complicado regime de administração que progressivamente aumenta a dose até 40 a 100 vezes o valor que os níveis fisiológicos podem alcançar (25).

Em seu uso médico legítimo, os EAA não são prescritos para atletas que estão simplesmente tentando ganhar musculatura. Eles podem levar os usuários a ganhar enorme massa muscular, muito além dos limites da musculatura que um homem comum pode obter sem estes fármacos (1).

Praticamente todos os EAA produzidos para fins humanos ou veterinários foram tomados por atletas. Quando o uso por atletas começou, os EAA $17 \alpha$-alquilados e outros compostos que se acreditava terem maiores efeitos anabolizantes que os efeitos androgênicos em relação à testosterona (os chamados "esteroides anabolizantes"), foram os mais comumente utilizados (20). Os EAA de uso veterinário frequentemente contêm os mesmos componentes, só que além de não serem puros, as doses também são muito maiores (15). Alguns exemplos de EAA disponíveis no mercado estão relacionados no Quadro 2. 
Quadro 2 - Esteroides anabólicos androgênicos (EAA) mais frequentemente utilizados com fins não terapêuticos.

\begin{tabular}{|l|l|l|}
\hline \multicolumn{1}{|c|}{ Nome Oficial } & \multicolumn{1}{|c|}{ Especialidade Farmacêutica } & Varenteral \\
\hline Boldenona (undecilanato) & Equipoiese & Oral \\
\hline Danazol & Danatrol & Oral/Parenteral \\
\hline Estanozolol & Winstrol & Oral \\
\hline Etilesterenol & Maxibolin \\
\hline Mesterelona & Proviron & Oral \\
\hline Metandrostenolona & Dianabol & Oral \\
\hline Metenolona (enantato) & Primobolan Depot & Parenteral \\
\hline Nandrolona (decanoato) & Deca-Durabolin & Parenteral \\
\hline Nandrolona (fenpropionato) & Durabolin & Parenteral \\
\hline 0xandrolona & Anavar & Oral \\
\hline 0ximetolona & Anadrol & Oral \\
\hline Testosterona & Andriol & Parenteral \\
\hline Testosterona & Testa C & Parenteral \\
\hline Testosterona (cipionato) & Testex & Parenteral \\
\hline Testosterona (enantato) & Testoviron Depot & Parenteral \\
\hline Testosterona (propionato) & Testex & Parenteral \\
\hline
\end{tabular}

Fonte: adaptado de Hernández (2004) (39).

Deve ser enfatizado que os EAA sozinhos não são necessariamente efetivos em suas propostas. É a sua combinação com intenso exercício físico e uma dieta rica em proteínas que é mais eficaz em proporcionar força e ganho muscular (13).

\section{EFEITOS ADVERSOS RELACIONADOS AO USO DE EAA}

Alguns dos distúrbios relacionados ao uso dos EAA são reversíveis e, muitos são de manifestação tardia, o que contribui para uma forte tendência ao seu abuso, pelo fato de o usuário nem sempre perceber de imediato o prejuízo para sua saúde (22).

Alguns efeitos colaterais da administração de doses farmacológicas de EAA ocorrem com todos os EAA e em todas as circunstâncias, mas outros só ocorrem com alguns EAA ou em certas circunstâncias. Todos os EAA suprimem a secreção de gonadotropina quando tomados em altas doses, suprimindo assim a função testicular endógena. $\mathrm{O}$ resultado é a diminuição da produção endógena de testosterona e esperma, levando à redução da fertilidade. Se a administração continuar durante muitos anos, o tamanho dos testículos pode diminuir. A testosterona e a produção de esperma geralmente voltam ao normal alguns meses após a suspensão do tratamento, mas pode levar mais tempo. Altas doses de EAA também causam eritrocitose (20).

EAA que podem ser convertidos em estrogênios, como a própria testosterona, causam ginecomastia quando administrados em altas doses $(20,26)$.

Os EAA 17 $\alpha$-alquilados são os únicos que causam hepatotoxicidade. Esses EAA parecem ter mais probabilidade do que outros, quando administrados em altas doses, de alterar as concentrações séricas de lipídios, especificamente de diminuir o colesterol HDL e aumentar o LDL $(20,27)$. Como exemplos desta classe de anabolizantes podem ser citados: danazol, metiltestosterona, metandrostenolona, oximetalona, oxandrolona e estanozolol (28).

Os efeitos adversos físicos e psicológicos dos EAA permanecem incompletamente documentados, havendo mais comumente envolvimento hepático, endócrino, músculo-esquelético, cardiovascular, imunológico, reprodutivo e psicológico, que podem ser divididos em três tipos: efeitos virilizantes; efeitos feminilizantes, mediados pelos metabólitos estrogênicos do EAA (Quadro 3 ); e efeitos tóxicos, geralmente mediados por mecanismos incertos (29). 
Parkinson \& Evans (2006), com o objetivo de identificar as tendências atuais dos hábitos de administração de fármacos dos usuários de EAA nos EUA, usaram como metodologia de coleta de dados, a aplicação de questionário anônimo em um site popular entre os usuários de EAA (30).

Quadro 3 - Efeitos adversos dos Esteroides anabólicos androgênicos (EAA)

\section{Endócrino/Reprodutivo homens:}

- Menor produção de hormônios (F)

- Atrofia testicular (F)

- Oligo/Azoospermia (F)

- Ginecomastia (F)

- Hipertrofia prostática (V)

- Carcinoma prostático

- Priapismo (V)

- Alteração do metabolismo glicídico (resistência à insulina, intolerância à glicose) ( $\mathrm{F}$ )

- Alteraçãodoperfiltireóideo (diminuiçãodeT3,T4,TSHeTBG)

- Impotência (F)

\section{Endócrino/Reprodutivo mulheres:}

- Masculinização (V)

- Hirsurtismo (V)

- Voz mais grave $(\mathrm{V})$

- Hipertrofia de clitóris (V)

- Atrofia mamária (V)

- Irregularidades menstruais (oligo/amenorréia) (V)

- Aumento da libido (V)

- Diminuição das gorduras corporais (V)

- Alteração do metabolismo glicídico (resistência à insulina, intolerância à glicose) (F)

- Alteração do perfil tireóideo (diminuição T3, T4, TSH e TBG)

\section{Cardiovascular/Hematológico:}

- Aumento do colesterol total

- Diminuição do colesterol HDL

- Aumento do colesterol LDL

- Hipertensão (retenção de sódio e água)

- Anormalidades hematológicas, como aumento da agregação plaquetária, com aumento das proteínas de coagulação facilitando a possibilidade de trombose e IAM

- Infarto miocárdico

- Hipertrofia de ventrículo esquerdo

- Acidente cerebrovascular

\section{Miscelânea:}

- Transmissão de HIV por compartilhar agulhas

- Possivelmente maior risco para doenças malignas

- Podem piorar ou induzir apneia obstrutiva do sono

\section{Renal:}

- Elevação da creatinina (T)

- Tumor de Wilms (T)

\section{Hepático:}

- Lesão hepática (T)

- Testes de função hepática alterados (T)

- Icterícia colestática (T)

- Carcinoma hepatocelular (mais de 24 meses de uso) (T)

- Peliose hepática (formação de "saculações de conteúdo sanguíneo" que podem romper matando por hemorragia - mais de 6 meses de uso) (T)

- Hepatoma, adenoma hepático (T)

- Hepatite (T)

- Sangramento de varizes por hipertrofia porta secundária à hiperplasia modular regenerativa $(T)$

Dermatológico:

- Acne (V)

- Alopecia (V)

\section{Psicológicos:}

- Comportamento agressivo (V)

- Aumento/diminuição da libido

- Flutuações repentinas do humor (T)

- Dependência (T)

- Psicose (T)

- Episódios maníacos e/ou depressivos (T)

- Ideação/tentativa de suicídio (T)

- Depressão quando da retirada (T)

- Ansiedade (T)

- Euforia (T)

- Irritabilidade $(\mathrm{T})$

\section{Subjetivo:}

- $\operatorname{Edema}(\mathrm{T})$

- Espasmo muscular

- Aumento do débito urinário

- Uretrite

- Dor escrotal

- Cefaleia (T)

- Tontura (T)

- Náusea (T)

\section{Musculoesquelético:}

- Risco aumentado de lesão musculotendinosa

- Necrose avascular de cabeça femoral

- Fechamento prematuro da epífises (adolescentes) (V)

V - Virilizantes; F - Feminilizantes; T - Tóxicos

Fonte: adaptado de Lise (1999) (29).

Os autores desenvolveram um questionário que possibilitasse uma compreensão profunda sobre o padrão de dosagem, regimes, demografia, acessórios utilizados no uso, e efeitos colaterais comuns entre os usuários. Os primeiros 500 usuários que responderam ao questionário foram incluídos no estudo. Destes 500 usuários, 98,8\% são do sexo masculino, sendo que des- 
tes, 78,4\% são atletas não competitivos e fisiculturistas recreativos que não participam de nenhum evento esportivo competitivo e não atletas que autoadministram EAA por razões cosméticas, com intenção única de melhorar a aparência física. Quase 100\% dos participantes reportaram efeitos colaterais subjetivos com o uso de EAA e $70 \%$ experimentaram três ou mais sintomas adversos. Um achado importante é que os efeitos adversos induzidos pelos EAA não detêm aumentos nas doses desses fármacos por parte dos usuários. Uma prática comum é a autoadministração de medicamentos adicionais para aliviar ou prevenir efeitos colaterais induzidos por EAA (30), como o uso de clomifeno, capaz de mascarar os efeitos androgênicos, e diuréticos, que diminuem o acúmulo de fluido provocado por estes agentes (31).

Um estudo realizado por alunos dos cursos de graduação e doutorado da Faculdade de Odontologia de Piracicaba e da Universidade Estadual de Campinas mostrou que a utilização de EAA em altas doses acentua o aumento do coração e que esta hipertrofia está associada a um menor rendimento cardíaco, pois há diminuição dos ventrículos cardíacos. O estudo foi realizado com ratos, em laboratório, e levou quatro anos para ser concluído. Até então, não se sabia como as alterações cardíacas eram causadas. Eles foram submetidos a treinamento físico de alta intensidade e tratados com doses 100 vezes maiores do que as doses terapêuticas do EAA nandrolona (dose equivalente à utilizada por atletas $\mathrm{e}$ frequentadores de academias). Eles constataram que, ao contrário do que a maioria das pessoas pensa, o EAA não causa somente aumento do músculo, mas também de fibras de colágeno no tecido cicatrizante, que altera a função elétrica do coração. As alterações podem estar relacionadas a casos de parada cardíaca e morte súbita em atletas usuários de EAA (32).

Mello et al. (2005) mostraram que o uso de EAA resulta na diminuição da eficiência do sono e no aumento da latência deste, trazendo prejuízos à qualidade do sono (33). Quando a sobrecarga imposta pelo exercício, por si só, é demasiadamente alta, ocorre uma influência negativa direta sobre a qualidade do sono, o que piora a qualidade de vida e diminui a produtividade no trabalho.

A compulsão pela prática de atividade física pode ser prejudicial à liberação regular de hormônios, quando não forem respeitados os horários adequados. Os ritmos diários, que controlam muitas de nossas funções fisiológicas, são altamente influenciados pelo exercício físico, como, por exemplo, as alterações hormonais e o ciclo sono-vigília. Assim, o exercício físico noturno pode atrasar a curva circadiana de hormônio tireoestimulante (TSH) e melatonina em humanos, sendo que o deslocamento de fase pode ser determinado pela duração e pela intensidade do exercício físico de forma compatível com a variação individual (33).
Muitos dados sobre efeitos em longo prazo do uso de EAA em humanos são mais provenientes dos relatos de casos do que de estudos epidemiológicos formais. Dos casos relatados, a incidência de efeitos letais parece ser baixa, mas os efeitos adversos sérios talvez sejam pouco reconhecidos ou sub-relatados, especialmente porque eles podem ocorrer muitos anos mais tarde. Assim como as complicações de saúde provocadas pelo abuso de EAA, a prevalência de casos extremos de violência e desordens de comportamento parecem ser baixas, mas isto talvez se deva à falta de conhecimento de casos (5).

Em seu estudo, Frizon et al. (2005) verificaram que cerca de $63 \%$ dos usuários acreditavam que o uso em associação com outros fármacos (insulina e hepatoprotetores, p.ex.) poderia reduzir os efeitos adversos dos EAA (17). Entretanto não há, de fato, evidência científica da eficácia dos fármacos utilizados dessa maneira, sem que aumente a probabilidade de ocorrência de efeitos adversos graves. Mais de $50 \%$ das pessoas que relataram uso de EAA (14 usuários), também reportaram efeitos adversos. Hipertensão e alterações psíquicas (aumento de agressividade e alteração de humor) foram os efeitos mais comuns reportados pelos usuários. Os autores relataram ainda que há um fator psicológico que faz com que os usuários de EAA tenham uma sensação aumentada de bem-estar e de autoconfiança, além da exacerbação de comportamento agressivo.

Os efeitos colaterais em curto prazo podem ser particularmente mais perigosos em adolescentes mais jovens, com a interrupção do crescimento, e nas mulheres, causando danos permanentes à voz e aos órgãos genitais. Os EAA injetáveis oferecem o risco de contaminação com o vírus HIV e da hepatite se as agulhas forem compartilhadas (15).

\section{Efeitos adversos psiquiátricos}

Embora os EAA raramente causem problemas clínicos imediatos, eles são realmente perigosos, especialmente por causa de seus efeitos psiquiátricos. Enquanto tomam EAA, alguns homens desenvolvem sérias alterações de humor, que vão desde irritabilidade branda à grande agressividade, não raro acompanhada por grosseiro prejuízo de julgamento e mania de grandeza. Em casos raros, os EAA podem até provocar as chamadas ilusões psicóticas (crença de conspirações contra o indivíduo, p.ex.) (1,34).

Em vários estudos com espécies animais comumente foi observada uma correlação entre os níveis de testosterona endógena e o comportamento agressivo. Entretanto, os achados em humanos foram menos consistentes: nos estudos clínicos, o comportamento agressivo e os níveis de testosterona endógena não foram bem correlacionados (2). 
Nos Estados Unidos foi feito um amplo estudo com usuários de EAA, obtendo como resultado que 25\% dos indivíduos sofriam de algum tipo de transtorno de humor, desde mania e transtorno bipolar até depressão profunda (6).

Em contraste aos poucos achados psiquiátricos nos estudos clínicos e laboratoriais, estudos naturalísticos de atletas com frequência relatam sintomatologia psiquiátrica importante com o uso de EAA. Em primeiro lugar vêm os relatos de caso que descrevem indivíduos com sintomas característicos de psicose ou mania associados com exposição à EAA e sintomas depressivos na abstinência desses agentes. Muitos também são os relatos de atos violentos e crimes, inclusive assassinato, cometidos por indivíduos que nunca tiveram comportamento comparável antes do uso de $\operatorname{EAA}(18,34)$.

Alguns estudos revelam que os EAA podem causar dependência, eventualmente levando à síndrome de abstinência, que pode desencadear crises comportamentais. Esta síndrome aparece em aproximadamente 14-57\% dos casos, nos quais se percebe sintomas como: perda de controle, depressão, fadiga, inquietação, perda do apetite, insônia, decréscimo da libido e dores de cabeça $(6,34)$.

Alguns indivíduos que fazem uso abusivo de EAA e cometeram atos agressivos, como briga física ou crimes à propriedade, geralmente relatam que têm estes comportamentos mais frequentemente quando tomam EAA do que quando estão livres desses fármacos. Um estudo realizado em 2006 sugeriu que os efeitos vistos sobre o humor e o comportamento durante o abuso de EAA podem resultar de mudanças hormonais secundárias (5).

Cientistas tentaram testar a associação entre EAA e o desenvolvimento de comportamentos agressivos administrando altas doses de EAA ou placebo por dias ou semanas a voluntários humanos e então pediram a eles que relatassem seus sintomas comportamentais. Quatro estudos foram conduzidos. Em três deles, altas doses de EAA produziram maiores sentimentos de irritabilidade e agressividade do que o placebo, entretanto os efeitos pareceram ser altamente variáveis entre diferentes indivíduos. No outro estudo, os EAA não geraram tais sintomas. Uma possível explicação, de acordo com as pesquisas, é que alguns, mas não todos EAA, aumentam a irritabilidade e a agressividade (5).

A influência de EAA no cérebro é difícil de interpretar, devido à incerteza de que eles cruzam a barreira hemo-liquórica e de quais são produzidos localmente em diferentes partes do cérebro e a interação e conversão entre eles e outras variáveis endócrinas modificando o comportamento. $\mathrm{O}$ fato é que há uma alta concentração de aromatase em várias regiões do cérebro (35).

\section{O PAPEL DO FARMACÊUTICO NO USO RACIONAL DE ESTEROIDES ANABÓLICO ANDROGÊNICOS (EAA)}

O farmacêutico, embasado em seus conhecimentos farmacológicos sobre os EAA, principalmente no que diz respeito às suas indicações médicas de uso, deve estar apto a reconhecer os diversos casos em que há uma tentativa de uso ilícito desses fármacos, mesmo quando o paciente estiver em poder de uma receita médica ao solicitar a sua administração, a fim de prestar uma orientação farmacêutica voltada ao desencorajamento do abuso de tais fármacos.

A orientação farmacêutica aos potenciais usuários de EAA permite a estes conhecer os riscos relacionados ao uso abusivo destas substâncias e, assim, decidirem conscientemente pela exposição ou não a tais riscos.

Os usuários e os potenciais usuários de EAA devem ser informados que forçar a natureza além do que é saudável e razoável pode ter um impacto devastador sobre o desenvolvimento emocional e físico (1).

A figura do farmacêutico emergiu no campo dos esportes. Com a proliferação do uso e abuso de fármacos e de suplementos alimentares em esportes, o profissional farmacêutico passou a desenvolver papel-chave no combate ao uso ilícito de fármacos e na prevenção do uso inadvertido de substâncias banidas para atletas. $\mathrm{O}$ farmacêutico deve considerar as necessidades especiais dos atletas ao dispensar medicamentos e ao recomendar produtos não prescritos e dieta suplementar (13).

Uma pesquisa dos programas educacionais sobre EAA mostrou que simplesmente ensinar os estudantes sobre os efeitos adversos desses fármacos não é capaz de convencer os adolescentes de que eles podem ser adversamente afetados e nem desencoraja o uso futuro de EAA por indivíduos jovens (5). É preciso mostrar aos jovens que os riscos do abuso de EAA à saúde em longo prazo são realmente perigosos, enfatizar que seus efeitos adversos podem gerar sérios problemas psiquiátricos, afetivos e até judiciários sem, no entanto, omitir os benefícios estéticos de seu uso. Assim, os jovens têm acesso a uma abordagem mais realista sobre os EAA e podem julgar com segurança a viabilidade deste uso ilícito.

Lima \& Cardoso (2004) investigaram, por meio de questionários, os conhecimentos e opiniões sobre o uso de EAA entre jovens em nossa sociedade, visando levantar percepções presentes nesse universo sobre questões relevantes relacionadas a esses fármacos (36). Participaram da pesquisa 242 jovens com idade média de 16 anos, praticantes de musculação em academias por um período médio de 7,4 meses. Investigou-se a maneira como se tem acesso às informações sobre esses fármacos, o conhecimento sobre os efeitos no organismo e algumas relações sociais envolvidas com o uso. Os 
resultados apontaram que os participantes da pesquisa apresentam um conhecimento sobre várias questões relacionadas aos EAA compatível com os conhecimentos científicos disponíveis. Nesse momento deve-se refletir sobre até que ponto a quantidade e a qualidade da informação disponível se relacionam com a prevenção do abuso, devendo ser analisado com cuidado também a percepção apresentada de que essas pessoas saberiam o que estão fazendo.

Os efeitos adversos dos EAA em curto prazo não são suficientes para intimidar um jovem que deseja alcançar um corpo perfeito em um período curto. Os jovens vivem o presente e os efeitos adversos mais ameaçadores à vida, por ocorrerem em longo prazo, não os preocupa.

Um programa chamado "Adolescents Training and Learning to Avoid Steroids (ATLAS)" está mostrando aos jogadores de futebol americano do ensino médio que eles não precisam de EAA para construir músculos fortes e para melhorar o desempenho atlético. O programa aumentou a prática de hábitos saudáveis dos jogadores e reduziu sua intenção de uso de EAA ao educá-los sobre os efeitos prejudiciais dos EAA e ao promover treinamento e nutrição como alternativa ao uso destes fármacos (5).

Estudos mostraram que 1 ano após a conclusão do programa, os estudantes de 15 turmas do ensino médio treinados, comparados com um grupo-controle, apresentaram metade da incidência de novos casos de abuso de EAA e menos intenção de abuso no futuro. Além do aumento da proteção contra EAA e menor interesse em experimentá-los, os estudantes têm melhor conhecimento de alternativas ao abuso de EAA e maior conhecimento sobre dietas suplementares (5).

É importante ressaltar que os farmacêticos que atuam em drogarias podem exercer grande influência sobre o uso ilícito de EAA, desencorajando seu uso, prestando orientação farmacêutica pertinente e exigindo a receita médica, de acordo com a Portaria SVS/MS n ${ }^{\circ}$. 344, de 12 de maio de 1998, que aprova o Regulamento Técnico sobre substâncias e medicamentos sujeitos a controle especial para a sua dispensação (37).

Os farmacêuticos podem também desenvolver e executar programas educativos sobre os EAA em academias junto aos jovens praticantes de musculação, em faculdades de educação física e em escolas com jovens que futuramente poderão se expor aos meios onde o abuso de EAA está presente.

É preciso alertar a população para o fato de que o protótipo de beleza, que hoje é imposto à sociedade, só pôde ser construído a partir do uso de doses suprafisiológicas de EAA e que, assim sendo, aqueles indivíduos que exibem corpos musculosos inatingíveis somente com dedicação à prática da musculação abusaram de substâncias ilícitas e arriscaram a própria saúde para ter tal aparência. Dessa forma, os jovens talvez passem a entender que seus corpos não estão desajustados, mas sim dentro de um perfil muscular normal que um organismo humano é capaz de manter fisiologicamente.

\section{DISCUSSÃO}

Em uma sociedade cada vez mais voltada para o aspecto visual da população e objetos, a busca pelo corpo perfeito tornou-se uma obsessão. $\mathrm{O}$ "mercado da beleza" é hoje um grande vilão junto à população, que não mede esforços na busca por um padrão estético muitas vezes inatingível, lançando mão de artifícios potencialmente danosos à saúde.

Os EAA despontam como um dos grandes destaques desta jornada pela perfeição.

Existem muitas indicações médicas para o uso dos EAA, como no hipogonadismo masculino e no tratamento da perda de massa muscular em pacientes com AIDS. Entretanto, verifica-se que atualmente é o uso ilícito que vem crescendo de forma preocupante entre a população, principalmente entre jovens praticantes de musculação, que buscam o efeito anabólico do fármaco sobre a massa muscular, esquecendo-se das ações androgênicas que frequentemente se apresentam associadas a este efeito.

Os efeitos adversos psiquiátricos são outra grande preocupação. Existem vários relatos de caso e com observações científicas que deixam muito claro a relação entre os EAA e a ocorrência de sérios problemas psiquiátricos. É preocupante o fato destes efeitos adversos não intimidarem os jovens quanto ao uso de tais fármacos.

A participação efetiva do profissional farmacêutico em um trabalho educativo direcionado aos usuários de tais substâncias é de suma importância, atuando de forma decisiva no desencorajamento do uso de EAA, procurando sempre abordagens que fujam das tradicionais campanhas de conscientização, que poucos resultados têm obtido nos últimos anos.

\section{CONCLUSÃO}

O culto ao corpo tem desencadeado medidas extremas na busca por um ideal de beleza inatingível para a maior parte da população, dentre os quais se destaca o uso de esteroides anabólicos androgênicos (EAA), fármacos altamente eficazes em sua proposta de desenvolvimento muscular, mas potencialmente perigosos. $\mathrm{O}$ farmacêutico, através de seus conhecimentos sobre medicamentos, assume papel fundamental na educação de usuários de EAA, esclarecendo-os sobre os riscos inerentes a tal prática, atuando de forma decisiva no desencorajamento do uso, utilizando abordagens que fujam das tradicionais campanhas de conscientização. 


\section{REFERÊNCIAS}

1. Pope Jr. HG, Phillips KA, Olivardia R. O Complexo de Adônis: a obsessão masculina pelo corpo. Rio de Janeiro: Campus. 2000. 316p.

2. Hartgens F, Kuipers H. Effects of androgenic-anabolic steroids in athletes. Sports Medicine. 2004; 34(8): 513-554.

3. Lamb DR. Uso abusivo de esteroides anabolizantes no esporte. Nutrição no Esporte. 1996; 5.

4. Basaria S. Androgen abuse in athletes: detection and consequences. J Clin Endocrinol Metabol. 2010; 95(4): 1533-43.

5. NIH. National Institute of Health. Research Report Series - Anabolic Steroid Abuse. Estados Unidos: U.S. Department of Health and Human Services. 2006. [03 dez. 2006] Disponível em: http://www. drugabuse.gov/researchreports/steroids/ anabolicsteroids4.html.

6. Martins CM, Carijó FH, Almeida MC, Silveira M, Mirailh MXN, Peixoto MM, Martins R, Ramalho TM, Sholl-Franco A. Efeitos psicológicos do abuso de anabolizantes. Ciências \& Cognição. 2005; 2(5): 84-91.

7. Estevão A, Bagrichevsky M. Cultura da "corpolatria" e body-building: notas para reflexão. Rev Mackenzie de Educação Física e Esporte. $2004 ; 3(3)$ : $15-27$

8. Souza ES, Fisberg M. O uso de esteroides anabolizantes na adolescência. Rev Nutrição em Pauta. 2002; 54.

9. Hakansson A, Mickelsson K, Wallin C, Berglund M. Anabolic androgenic steroids in the general population: user characteristics and associations with substance use. Eur Addiction Res. 2012; 18(2): 83-90.

10. CEBRID. Centro Brasileiro de Informações sobre Drogas Psicotrópicas. Esteroides anabolizantes. 2003. [26 jun. 2006]. Disponível em: http://www.saude.inf.br/cebrid/cestero.htm.

11. Kanayama G, Boynes M, Hudson JI, Field AE, Pope Jr. HG. Anabolic steroid abuse among teenage girls: an illusory problem? Drug Alcohol Depend. 2007; 88(2-3): 156-62.

12. CEBRID. Centro Brasileiro de Informações sobre Drogas Psicotrópicas. Esteroides anabolizantes. 2009. [20 jun. 2010]. Disponível em: http://www.saude.inf.br/cebrid.

13. Ambrose PJ. Drugs use in sports: a veritable arena for pharmacists. Amer Pharmacists Assoc. 2004; 44(4): 501-516.

14. Andrade AG, Duarte P do C, Barroso LP, Nishimura R, Alberghini DG, de Oliveira LG. Use of alcohol and other drugs among Brazilian college students: effects of gender and age. Rev Bras Psiquiatria. 2012; 34(3): 294-305.

15. SBEM-DF. Sociedade Brasileira de Endocrinologia e Metabologia Regional do Distrito Federal. Esteroides Anabolizantes e os Jovens. 2004. [27 dez. 2006]. Disponível em: http://www.hormone.org/pdf/ portuguese/anabolic_steroids_portuguese.pdf.

16. Wichstrom L. Predictors of future anabolic steroid use. Medicine \& Science in Sports \& Exercise. 2006; 38(9): 1578-1583.

17. Frizon F, Macedo SMD, Yonamine M. Uso de esteroides andrógenos por praticantes de atividade física das principais academias de Erechim e Passo Fundo/RS. Rev Ciências Farmac Básica e Aplicada. 2005; 26(3): 227-232.

18. Peluso MAM, Assunção SSM, Araújo LASB, Andrade LHG. Alterações psiquiátricas associadas ao uso de anabolizantes. Rev Psiquiatria Clinica. 2000; 27(4): 229-236.

19. Andrade TU, Serafini M, Cominotti W. Perfil dos usuários de esteroides anabólicos androgênicos em academias da grande Vitória. [Trabalho de Conclusão de Curso]. Vila Velha, Brasil: Universidade Vila Velha. 2006
20. Hardman JG, Limbird LE (Ed). Goodman \& Gilman: as bases farmacológicas da terapêutica. 10.ed. Rio de Janeiro: McGraw-Hill. 2005.

21. Katzung BG. Basic \& Clinical Pharmacology. 9.ed. United States of America: The McGraw-Hill Companies. 2004.

22. Machado NHS. Esteroides anabolizantes: efeitos anabólicos e andrógenos. Rev Ciências Farmacêuticas. 2003; 26(3): 227-232.

23. Cunha TS, Tanno AP, Moura MJCS, Marcondes FK. Relação entre a administração de esteróide anabólico androgênico, treinamento fisico aeróbio e supercompensação do glicogênio. Rev Bras Medicina do Esporte. 2005; 11(3): 187-192.

24. Bonetta L. The steroid story. American School Board Journal. 2004; 191(8): 19-21

25. Hall RCW. Abuse of supraphysiologic doses of anabolic steroids. Southern Medical Assoc. 2005; 14(3): 550-555.

26. Orlandi MA, Venegoni E, Pagani C. Gynecomastia in two young men with histories of prolonged use of anabolic androgenic steroids. J Ultrasound. 2010; 13(2): 46-8.

27. Awai HI, Yu EL, Ellis LS, Schwimmer JB. Liver toxicity of anabolic androgenic steroid use in an adolescent with nonalcoholic fatty liver disease. J Pediatric Gastroenterol and Nutrition. 2013; apr.4.

28. Lund BC, Perry PJ. Nonsteroid performance-enhancing agents in athletic competition: an overview for clinicians. Medscape Pharmacology Therapy. 2000; sept.7.

29. Lise MLZ. O abuso de esteroides anabólico-androgênicos em atletismo. Rev Assoc Médica Brasileira. 1999; 45(4): 364-370.

30. Parkinson AB, Evans NA. Anabolic androgenic steroids: a survey of 500 users. Medicine \& Science in Sports \& Exercise. 2006; 38(4): 644-651.

31. Vega CP. Sports and Substance Abuse. California. 2005. [19 dez. 2006]. Disponível em: http://www.medscape.com/viewarticle/51848.

32. Baptista LG. Anabolizante causa alteração cardíaca. Jornal de Piracicaba. 2006 [10 dez. 2006]. Disponível em: http://powdermix.com.br.

33. Mello MT, Boscolo RA, Esteves M, Tufik S. O exercício físico e os aspectos psicobiológicos. Rev Bras Medicina do Esporte. 2005; 11(3): 203-209.

34. Kanayama G, Brower KJ, Wood RI, Hudson JI, Pope Jr. HG. Issues for DSM-V: clarifying the diagnostic criteria for anabolic-androgenic steroid dependence. Am J Psychiatry. 2009; 166(6): 642-5.

35. Carruthers ME. Andrógenos e a barreira hemo-liquórica. Sociedade Brasileira de Endocrinologia e Metabologia (SBEM). 2006. [17 dez. 2006]. Disponível em: http://www.endocrino.org. br/ conteudo/artigos_exibe.php?idNot=14.

36. Lima F, Cardoso N. Abordagem sociológica sobre a percepção de indivíduos jovens em relação ao uso de esteroides anabólico-androgênicos. Rev Portug Ciências do Desporto. 2004; 4(2): 107-129.

37. BRASIL. Conselho Federal de Farmácia. Portaria 344. Disponível em: <http://www.cff.org.br/ Legisla\%C $3 \%$ A7\%C3\%A3o/Portarias/ port_344_98.html>. Acesso em: 21 jan. 2007.

38. Silva PRP, Danielski R, Czepielewski MA. Esteroides anabolizantes no esporte. Rev Bras Medicina no Esporte. 2002; 8(6): 235-243.

39. Hernández LS. Efectos adversos para la salud inducidos por los esteroides anabolizantes em un grupo controlado de fisioculturistas. Vector Plus. 2004; 54(24): 63-77. 